\title{
Campus Teaching Awards, Academic Year 2016-2017
}

PSA is pleased to recognize the recipients of campus-wide and departmental awards for teaching excellence during the 2016-2017 academic year. Their contributions to teaching, mentorship, and future students create a lasting legacy in political science. (Photos appear above recipient's name and institution.)

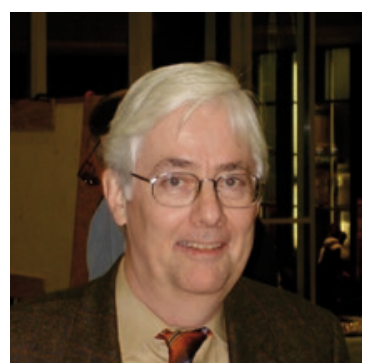

Christopher Achen, Princeton University, McGraw Center for Teaching and Learning Graduate Mentoring Award

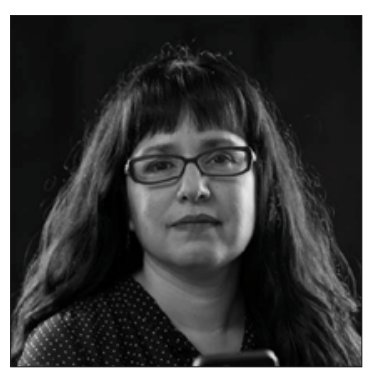

Janni Aragon, University of Victoria, Harry Hickman Alumni Award for Excellence in Teaching and Education Leadership

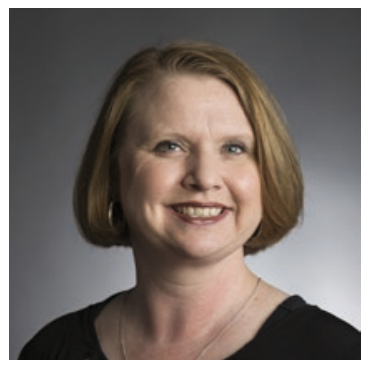

Amy Atchison, Valparaiso University, Valparaiso University Alumni Association's Distinguished Teaching Award

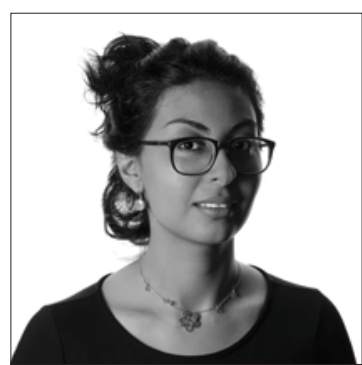

Nazgol Bagheri, University of Texas at San Antonio, President's Distinguished Achievement Award for Teaching Excellence

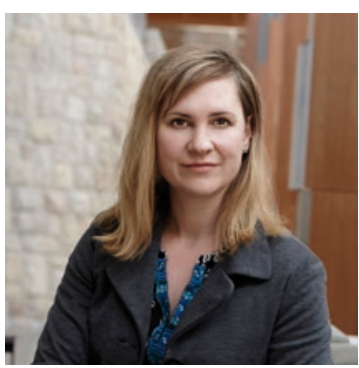

Colleen Bell, University of Saskatchewan, Provost's Outstanding New Teacher Award

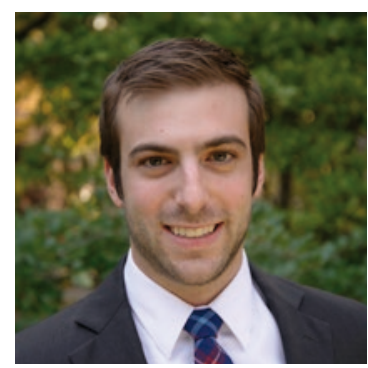

Nicholas Bell, University of Pennsylvania, Penn Prize for Excellence in Teaching by Graduate Students

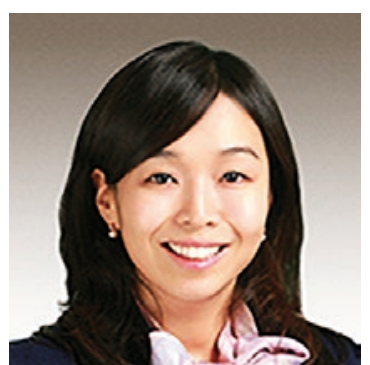

Ñusta Carranza Ko, Ohio Northern University, Student Advisory Board Outstanding Faculty Award

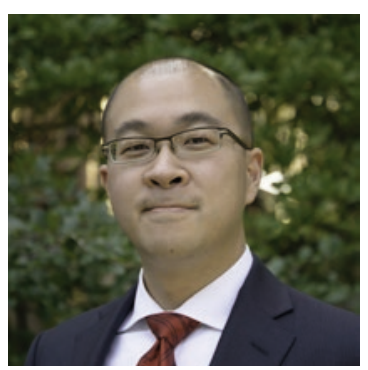

Brian C. Chao, University of Pennsylvania, Dean's Award for Distinguished Teaching by Graduate Students

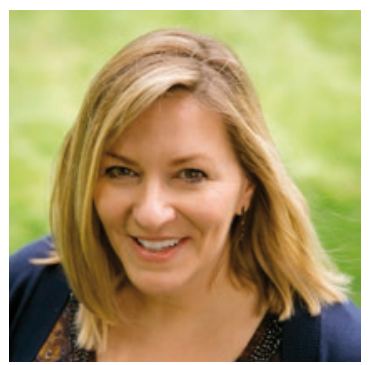

Tanya Corbin, Radford University, College of Humanities and Behavioral Sciences Distinguished Teaching Award 


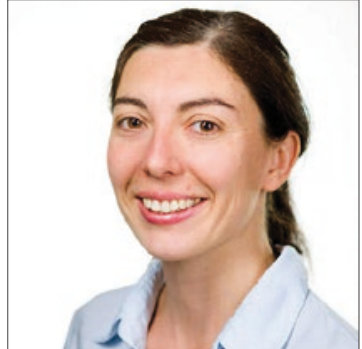

Cristina Corduneanu-Huci, Central European University, Central European University Distinguished Teaching Award

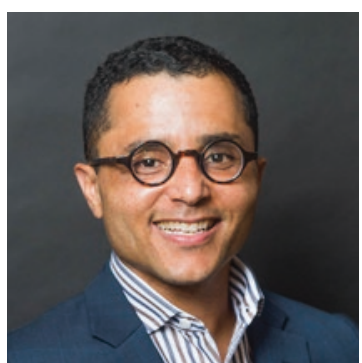

Heath Davis, Temple University, Eleanor Hofkin Award for Excellence in Teaching

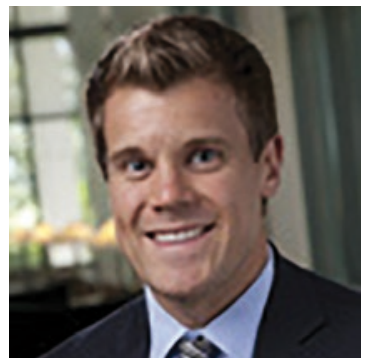

Robert DeLeo, Bentley University, Bentley University Innovation in Teaching Award

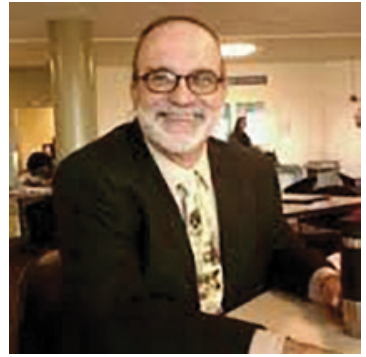

Gary Donato, Bentley University, Bentley University Innovation in Teaching Award

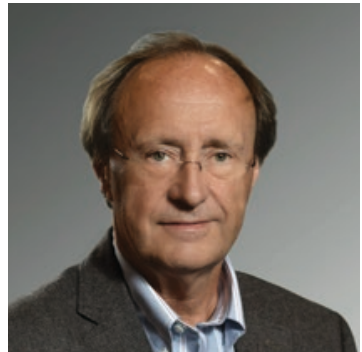

John E. Finn, Wesleyan University, 2017 Binswanger Prize for Excellence in Teaching

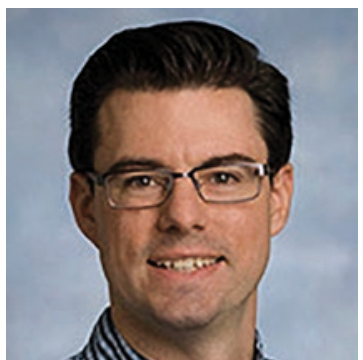

Elliott Fullmer, Randolph-Macon College, Thomas Branch Award for Excellence in Teaching

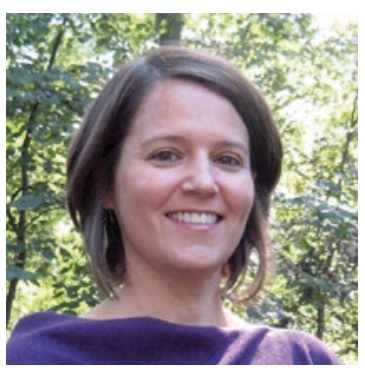

Jennifer Goett, Michigan State University, Teacher-Scholar Award

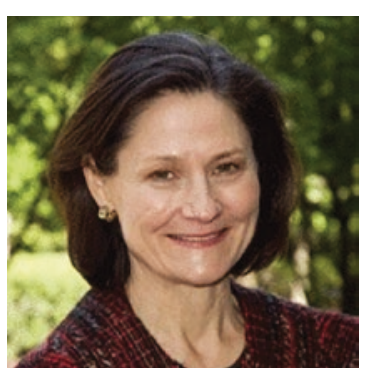

Marie Gottschalk, University of Pennsylvania, Ira H. Abrams Memorial Award for Distinguished Teaching

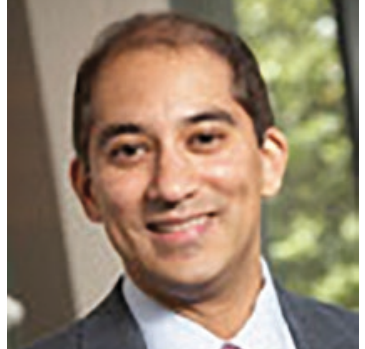

JeffGulati, Bentley University, Bentley University Innovation in Teaching Award

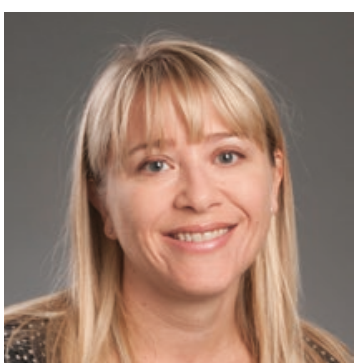

Lori Hausegger, Boise State University, Golden Apple Award

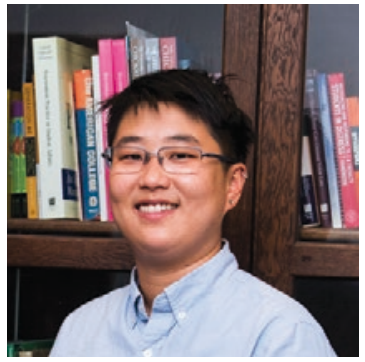

Omiela Hsu, University of Chicago, Wayne C. Booth Graduate Student Prize for Excellence in Teaching

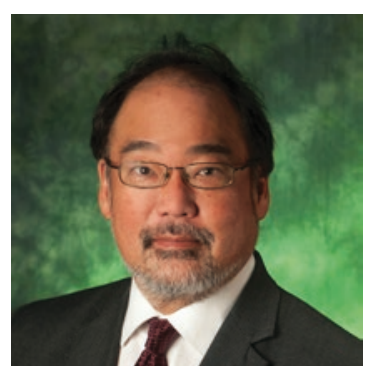

John Ishiyama, University of North Texas, Minnie Stevens Piper Professor Award 


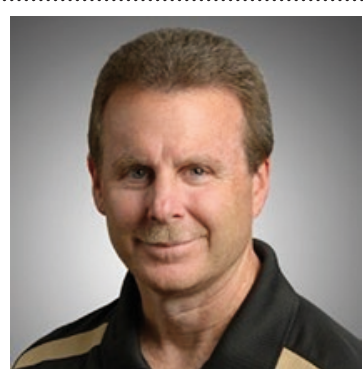

AubreyJewett, University of Central Florida, Teaching Incentive Program Award

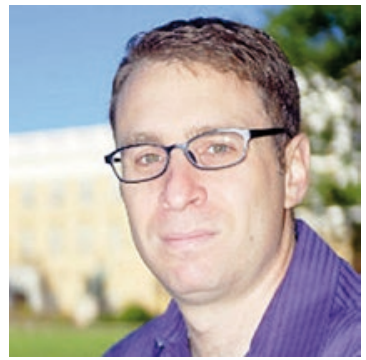

Daniel Kapust, University of Wisconsin, Madison, Class of 1955 Teaching Excellence Award

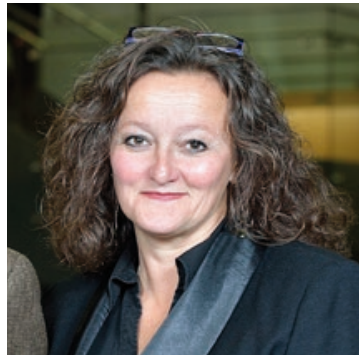

Kimi King, University of North Texas, J.H. Shelton Excellence in Teaching Award

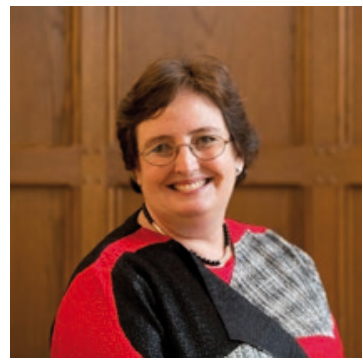

Robin Kolodny, Temple University, Temple University Great Teacher Award

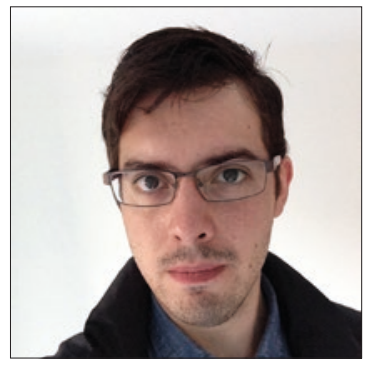

Steven McDowell, Notre Dame University, Outstanding Graduate Student Teaching Award

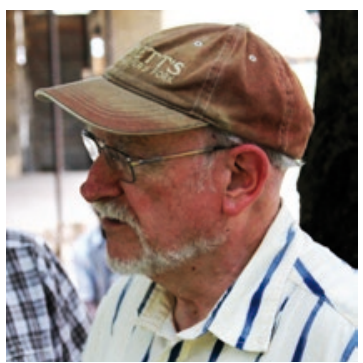

Ron Oakerson, Houghton College, Excellence in Teaching Award

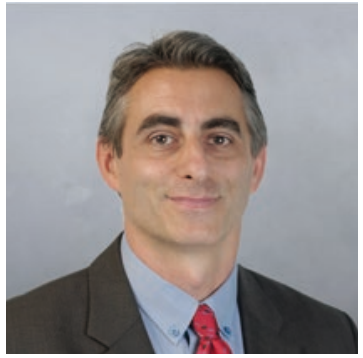

James DeShaw Rae, Sacramento State University, Outstanding Teacher Award

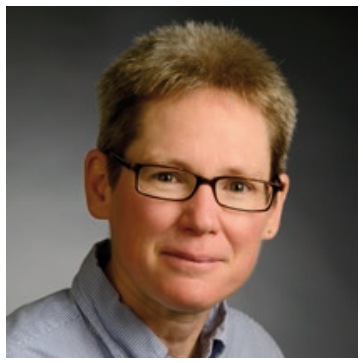

Ellen D.B. Riggle, University of Kentucky, William B. Sturgill Award for Outstanding Contributions to Graduate Education

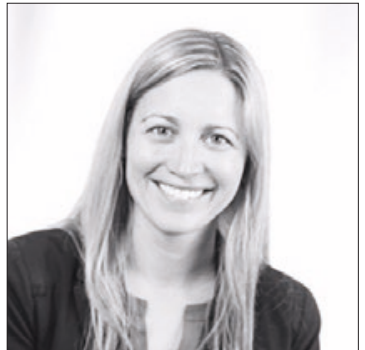

Sara Rinfret, University of Montana, Helen and Winston Cox Educational Excellence Award

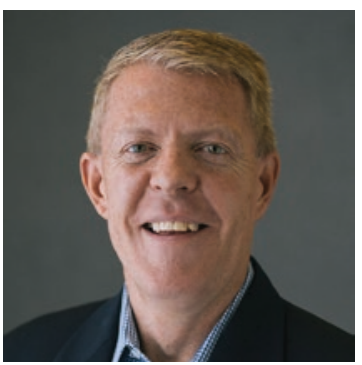

Brian Roberts, Principia College, Horace Edwin Harper Jr. and Evelyn Wright Harper Award for Teaching Excellence

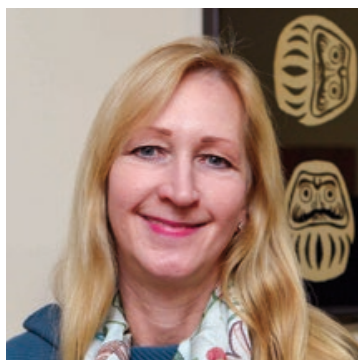

Frances McCall Rosenbluth, Yale University, The Lex Hixon '63 Prize for Teaching Excellence in the Social Sciences

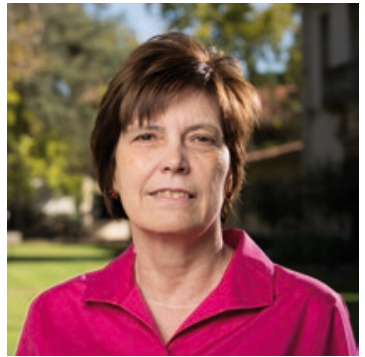

Jean Schroedel, Claremont Graduate University, The Claremont Consortium Teaching Award for Diversity 


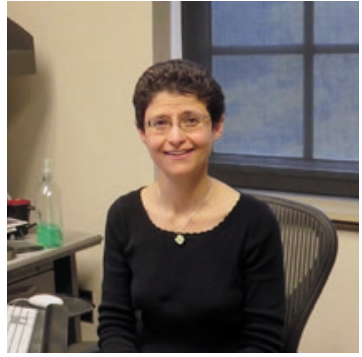

Noha Shawki, Illinois State University, Pi Sigma Alpha Excellence in Teaching Award; Hibbert R. Roberts Teaching Excellence Recognition Award

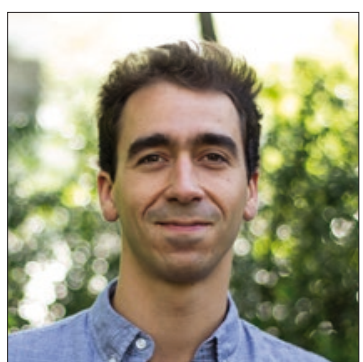

Nathaniel Shils, University of Pennsylvania, Dean's Award for Distinguished Teaching by Graduate Students

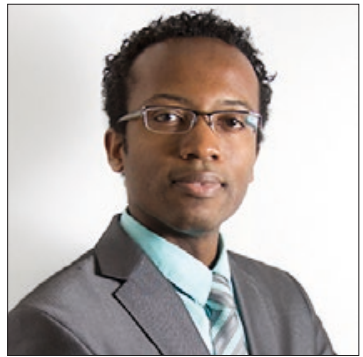

Landry Signé, University of Alaska, Anchorage, Chancellor's Award of Excellence in Teaching

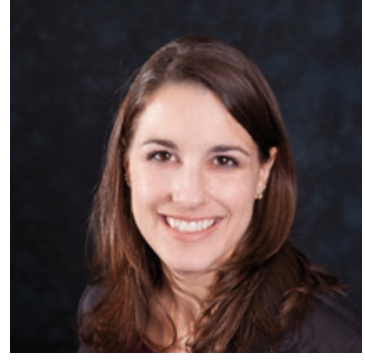

Elizabeth Simas, University of Houston, Provost's Core Award in Teaching Excellence

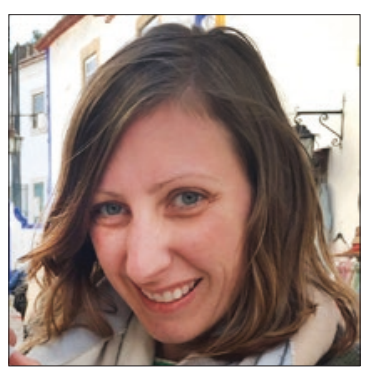

Erika Cornelius Smith, Nichols College, Rita A. Gatzke Memorial Student Government Appreciation Award

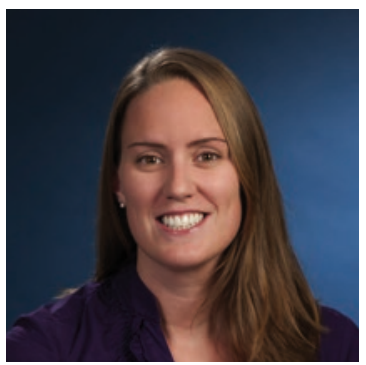

Patricia Stapleton, Worcester Polytechnic Institute, Romeo L. Moruzzi Young Faculty Award for Innovation in Undergraduate Education

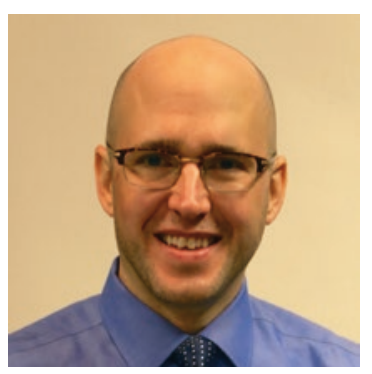

David Szymanski, Bentley University, Bentley University Innovation in Teaching Award

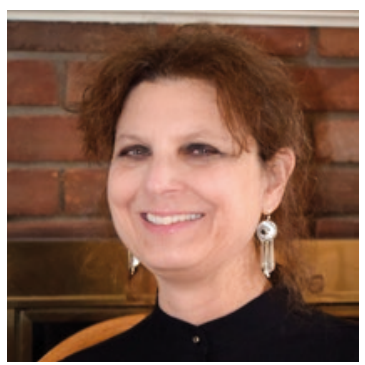

Colleen Tremonte, Michigan State University, President's Distinguished Teaching Award

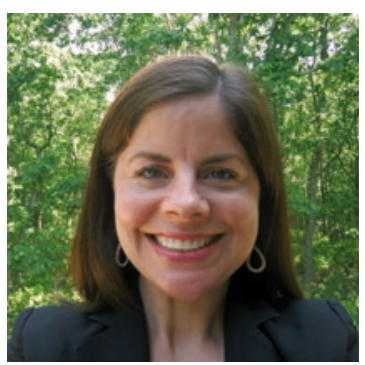

Tina Zappile, Stockton University, Faculty of the Year Award 